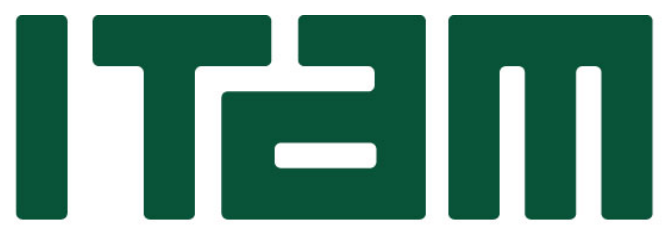

INSTITUTO TECNOLÓGICO AUTÓNOMO DE MÉXICO

CENTRO DE INVESTIGACIÓN ECONÓMICA

WORKING PAPER SERIES

Labor, Output and Consumption in Business Cycle Models of Emerging Economies: A Comment

Andrés Fernández

Universidad de los Andes

Felipe Meza

Instituto Tecnológico Autónomo de México

Octubre/2011

Working Paper 11-06 


\title{
Labor, Output and Consumption in Business Cycle Models of Emerging Economies: A Comment ${ }^{1}$
}

\author{
Andrés Fernández \\ Felipe Meza \\ Universidad de los Andes Instituto Tecnológico Autónomo de México
}

August 2011

\section{Introduction}

In an important work in the 2007 Journal of Political Economy, Mark Aguiar and Gita Gopinath (AG, henceforth) exploited the information in business cycles to identify the characteristics of productivity in a standard $\mathrm{SOE} / \mathrm{RBC}$ model using time series data from emerging and developed small open economies. Their main finding is that shocks to trend, rather than transitory fluctuations around a stable trend, are the primary source of fluctuations in emerging markets, and can properly account for the high consumption volatility that exceeds income volatility. Shocks to trend can also account for "sudden stops" in these economies. Two features of their analysis are: (i) the main results concerning the relative importance of trend shocks are robust to alternative preferences such as the quasi-linear ones introduced by Greenwood, Hercowitz, and Huffman (1988); and (ii) AG do not attempt to match the dynamics observed in hours or employment in these economies.

In this comment we assess the robustness of the findings of $A G$ if labor data is explicitly taken into account when measuring the relative importance of trend shocks in emerging economies. Our motivation is twofold. First, the behavior of the labor input has traditionally been of prime importance to business cycle theory. Second, and perhaps more important, at business cycle frequencies, labor dynamics in emerging economies differ in nontrivial ways

\footnotetext{
${ }^{1}$ We benefited from conversations with Gita Gopinath, Adam Gulan, Norman Loayza, P. Andrés Neumeyer, Martín Uribe and Carlos Urrutia. We thank Sergio Castellanos-Gamboa and Rodolfo E. OviedoMoguel for excellent research assistance. All errors and omissions are our own. Felipe Meza thanks the Asociacion Mexicana de Cultura A.C., and CONACYT (via research grant No. 81825) for financial support. Emails: andrfern@uniandes.edu.co, felipe.meza@itam.mx.
} 
from those observed in developed small open economies. Comparing Mexico and Canada the two countries AG studied more closely as representative emerging/developed economies-, employment is significantly more procyclical and volatile, relative to output, in the latter than in the former economy. It is therefore interesting for researchers of business cycles to ask whether or not trend shocks can also account for these differences across emerging and developed economies.

Our main findings can be summarized as follows. First, the model of AG -with CobbDouglas preferences-, henceforth the benchmark, is unable to reproduce qualitatively the procyclicality of labor in Mexico. Additionally, this manifests in sudden stop simulations where equilibrium labor rises, which is counterfactual. Second, there is a trade-off between having sizeable growth shocks, thereby having a good match in terms of relative consumption volatility, and having procyclical employment dynamics in the model. We show analytically that one cannot have a good match in both dimensions under the benchmark model of AG. Third, using quasi-linear preferences alone is not a remedy. Only when these preferences are assumed and the identification strategy explicitly takes into consideration labor dynamics can the modified AG model account for both the large volatility in consumption and the mild procyclicality of labor in Mexico. Fourth, when estimated with Canadian data, the modified model continues to favor the hypothesis that trend shocks are more important in Mexico than in Canada. Fifth, digging deeper into the measurement issues surrounding employment data in emerging economies that prevented AG from incorporating this information into their analysis, we find that the main difference between labor statistics in Mexico and Canada comes from the large informal labor in Mexico. It is in this dimension, when trying to match the dynamics of formal employment, that we find less support for trend shocks as being the major driving force of business cycles in emerging economies. The model faces a stronger tension between replicating the volatility of consumption and the high cyclicality of formal labor, becoming unable to match both simultaneously. We then conclude that future business cycle models of emerging economies ought to include employment data into their analysis, along with more detailed frictions in labor markets.

\section{Preliminaries}

Before presenting our analysis, we reproduce part of the model of AG to fix concepts. The production function is 


$$
Y_{t}=e^{z_{t}} K_{t}^{1-\alpha}\left(\Gamma_{t} L_{t}\right)^{\alpha}
$$

where

$$
\begin{gathered}
z_{t}=\rho_{z} z_{t-1}+\epsilon_{t}^{z},\left|\rho_{z}\right|<1 \\
\Gamma_{t}=e^{g_{t}} \Gamma_{t-1}=\prod_{s=0}^{t} e^{g_{s}} \\
g_{t}=\left(1-\rho_{g}\right) \mu_{g}+\rho_{g} g_{t-1}+\epsilon_{t}^{g},\left|\rho_{g}\right|<1
\end{gathered}
$$

and $\epsilon_{t}^{z}, \epsilon_{t}^{g}$ are distributed normally with means equal to zero and standard deviations $\sigma_{z}, \sigma_{g}$ respectively. Variable $z_{t}$ represents a shock to the transitory component of productivity. Variable $g_{t}$ represents a shock to the growth of productivity. We call it a growth shock. Variable $\Gamma_{t}$, which depends on the sequence of $g_{t}$, is the permanent component of productivity. We do not observe directly the values of the parameters ruling $z_{t}$ and $g_{t}$. We estimate them in the following section. The utility function used by AG is Cobb-Douglas

$$
u\left(C_{t}, H_{t}\right)=\frac{\left(C_{t}^{\gamma}\left(1-H_{t}\right)^{1-\gamma}\right)^{1-\sigma}-1}{1-\sigma}, \sigma>0,0<\gamma<1
$$

where $C_{t}$ is consumption and $H_{t}$ is labor. Alternatively, we use the GHH-type of preferences that have been used frequently in models of small open economies:

$$
u\left(C_{t}, H_{t}\right)=\frac{\left(C_{t}-\tau \Gamma_{t-1} H_{t}^{\nu}\right)^{1-\sigma}-1}{1-\sigma}, \sigma>0, \tau>0, \nu>1 .^{2}
$$

The values of parameters for both functions are the same as in AG for the Cobb-Douglas case, and the ones in Aguiar and Gopinath (2004) for the GHH case. In Table 1 we display the list of parameter values. ${ }^{3}$ As is well known, but important for our discussion, the key distinction between the two types of utilities is the income effect governing labor supply decisions in response to different shocks (see Aguiar and Gopinath, 2004; Neumeyer and Perri, 2005). While in the Cobb-Douglas case the labor supply will respond to changes in

\footnotetext{
${ }^{2}$ See Correia, Neves and Rebelo (1995) for a study of the properties of a small open economy model in which productivity has a deterministic trend, unlike in the model under analysis, and a stationary component. They analyzed the predictions of the model using either a Cobb-Douglas utility or a GHH one, and found that the model with the GHH function matched the data more closely.

${ }^{3}$ In the case of $\mu_{g}$ in all estimations we calibrate it using Table 4 in Aguiar and Gopinath (2004).
} 
the productivity process because of its impact on consumption, in the GHH case the labor supply is unmitigated by the response of consumption. Our exploration will assess results across these two types of preferences. ${ }^{4}$

\section{Alternative models and estimations: predicted busi- ness cycle statistics for Mexico}

In this section we analyze the implications of the benchmark model and carry out three variations. The sample we use is 1987:I - 2003:II, which is a subset of the sample in AG for which data on employment exists and that was also used by AG when computing Solow residuals for Mexico. The benchmark GMM estimation consists of estimating $\sigma_{g}, \sigma_{z}$ and $\rho_{g}$ matching the standard deviation of output, the standard deviation of consumption and the covariance of consumption and income. The benchmark estimation is estimation 3 in Table 4 in AG which we follow in order to maximize comparability between our results and theirs. ${ }^{5}$ We first modify the benchmark estimation by adding two moments of labor. The moments are the standard deviation of the cyclical component of HP-filtered employment, and the correlation between the cyclical components of employment and output. The second variation is to assume a GHH utility, while keeping the estimation as in the benchmark. The third variation is to assume a GHH utility and estimate parameters adding the two moments of labor. ${ }^{6}$

We present results in Table 2. The left part of the Table serves as a reference as it displays the properties of the data in the sample used in AG. It also reports the estimated values of parameters presented in that article and our replication. As seen in the Table, we closely match the estimated values of parameters. ${ }^{7}$ The right part of the Table presents the

\footnotetext{
${ }^{4}$ In separate experiments, not reported but available upon request, we also consider the type of preferences introduced by Jaimovich and Rebelo (2009), $u\left(C_{t}, H_{t}\right)=\frac{\left(C_{t}-\tau H_{t}^{\omega} X_{t}\right)^{1-\sigma}}{1-\sigma}$, where $X_{t}=C_{t}^{\omega} X_{t-1}^{1-\omega}, 0<\omega \leq 1$. The case $\omega=1$ corresponds to preferences in the class consistent with steady state growth discussed by King, Plosser and Rebelo (1988). The case $\omega=0$ corresponds to preferences in Greenwood, Hercowitz, and Huffman (1988). The Jaimovich-Rebelo preferences are consistent with steady state growth with $0<\omega \leq 1$.

${ }^{5} \mathrm{AG}$ report results from three additional estimations, where they modify the number of parameters, and moments used. Results on the size of the random walk component of productivity do not change much. We set $\rho_{z}$ equal to 0.95 as in Table 4 in AG.

${ }^{6}$ We use the computer codes that M. Aguiar and G. Gopinath have posted online. Specifically, we use their code that solves the model assuming a Cobb-Douglas utility. We also use their code that calculates predicted theoretical business cycle moments of HP-filtered data. We use our own code that solves the model in the case of a GHH utility, by making simple modifications to the code of the Cobb-Douglas case. We use the codes described in Burnside (1999) to carry out the GMM estimation. Our codes are available upon request.

${ }^{7}$ We start with this simple replication to verify that our codes are free of errors.
} 
main results. It first displays the properties of the data in the sample for which we have data on labor. Then it reports the results of the three variations we study.

The first result is that the benchmark (Cobb-Douglas utility, estimating $\sigma_{g}, \sigma_{z}$ and $\rho_{g}$, not using data on labor) implies a negative correlation between labor and output of -0.36, as can be seen towards the bottom of column 5. The benchmark has success predicting a volatility of consumption higher than the one of output, but does not have a good prediction regarding the labor correlation. Its value in the data is 0.55. The success and failure of the benchmark are evidently related because of the functional form chosen for preferences. Notice that the volatility of growth shocks is much bigger than the one of transitory shocks. When a large negative growth shock hits the economy, there is a large negative income effect that reduces consumption and increases labor supply. In equilibrium firms end up hiring more labor despite its reduced marginal productivity while, at the same time, output falls.

The second result is that the benchmark, modified by adding to the list of moments the standard deviation of labor and the covariance between labor and output, predicts a much smaller negative labor correlation. In fact it is close to zero. This result says that using information on labor goes in the direction of reducing the gap between the data and the model. This can be seen on column 6 . On the other hand, the volatility of consumption relative to the one of output falls slightly, which goes against matching the data.

These results indicate a trade-off arises between a good fit of the benchmark model in terms of relative consumption volatility and labor dynamics: in order to match the procyclicality of labor the model requires relatively mild growth shocks. This can be analytically pinned down by studying the equilibrium in the labor market which can be characterized as follows (in log-deviations from the steady state):

$$
\widehat{h}_{t}=(1-H)\left(\widehat{y}_{t}-\widehat{c}_{t}\right)
$$

where $H$ is the steady state level of labor. ${ }^{8}$ It is thus straightforward from this equilibrium condition that the trade-off arises because, to the extent that growth shocks deliver a large deviation of consumption relative to output, these shocks will also deliver a negative response of equilibrium labor. This is the reason why the estimated model in column 6 continues to perform poorly in matching the procyclicality of Mexican labor as doing it would require reducing the close match in terms of consumption volatility.

\footnotetext{
${ }^{8}$ In this equation, $\widehat{y}$ represents the log-deviation of detrended output from the steady state, $\widehat{c}$ is the log-deviation of detrended consumption from the steady state, and $\widehat{h}$ is the log-deviation of labor from the steady state.
} 
Our third result is that modifying the benchmark by using a GHH utility as was done by $A G$ in the working paper version of their work, is not enough to simultaneously achieve a high volatility of consumption and a positive correlation between labor and employment. Results from this experiment are shown in column 7. The model does predict a volatility of consumption bigger than the one of output, but also predicts a negative correlation of labor and output. This is due to the inclusion of cumulative growth in the disutility of work, as we comment below.

Our fourth set of results come from the combination of GHH utility and information on labor in the set of moments which yields a positive correlation between labor and output, as in the data. Simultaneously, this specification predicts a volatility of consumption bigger than the one of output, although smaller than in previous estimations. Results are shown in column 8. The correlation takes a value of 0.30 , and the ratio $\sigma_{c} / \sigma_{y}$ is equal to 1.22 . Evaluating the model along the dimension of simultaneously achieving a positive correlation of labor and high relative volatility of consumption, this version is the most successful of the four discussed. As before, results can be interpreted by studying the equilibrium in the labor market characterized as follows:

$$
\widehat{h}_{t}=\frac{1}{v} \widehat{y}_{t}
$$

Unlike in the Cobb-Douglas case, consumption will no longer play a role in the level of employment. Thus, the initial response of labor following growth shocks will always be positive, thereby reducing the trade-off between a good performance in the moments of labor or in the relative volatility of consumption. It should be noted, however, that the trade-off does not entirely disappear. Because of the inclusion of cumulative growth in the disutility of labor under the GHH case, a positive growth shock will reduce the labor supply after one period. This can be seen in the version of the previous equilibrium equation written in logs of the levels of the variables:

$$
\ln Y_{t}=\ln \frac{\tau \nu}{\alpha}+\ln \Gamma_{t-1}+\nu \ln H_{t}
$$

The difference between $y_{t}$ and $Y_{t}$ is that the former is detrended by $\Gamma_{t-1}$. Provided that positive growth shocks are large and increase the disutility of labor in the next period, this effect could deliver a countercyclical equilibrium labor, as was the case in the previous estimation under GHH but without including moments of labor.

In summary, while the benchmark model of AG is unable to reproduce the procyclicality 
of labor in Mexico, it is shown here that it is possible to simultaneously achieve a positive correlation between labor and output and a volatility of consumption higher than the one of output, conditional on using a GHH utility and including information on labor in the GMM estimation of productivity parameters. ${ }^{9}$ Additionally, the two measures of fit in the last two rows of Table 2 show that such specification has a superior fit to the data. ${ }^{10}$ We turn now to studying the predictions of the model in terms of sudden stops focusing our attention on labor dynamics.

\section{Sudden stop experiments}

We analyze the predictions of the model in times of sudden stops. Emerging economies have experienced important episodes in which they lose access to international financial markets. Our goal is to find the version of the model and estimation that has the best predictions regarding the behavior of variables during a sudden stop.

The methodology we follow includes defining a sudden stop and then simulating the model to obtain artificial episodes which we analyze. To carry out the simulations we use the estimated parameters found for Mexico. We define a sudden stop as Mendoza (2010). A sudden stop is a period in which output is at least one standard deviation below trend, and the ratio of net exports to output is at least one standard deviation above trend. We carry out 1000 simulations, each one of the same length as the one of the data sample we use, which is 66 quarters. In Figure 1, we make plots of output, labor and consumption three periods before and after a sudden stop. ${ }^{11}$ We plot the median across sudden stop episodes. Together with simulated data, we plot data from the Mexican Crisis of 1994-1995. We plot the logarithm of the level of each variable, detrended with the HP-filter. There was a large fall in output and consumption in 1995, together with a fall in labor. In the second quarter of 1995 Mexican GDP deviated $-7.8 \%$ from the trend. This is the quarter in which HP-filtered GDP reaches its trough. The standard deviation of the output gap for the entire sample is

\footnotetext{
${ }^{9}$ We also carried out the estimation with moments of labor with preferences of the Jaimovich-Rebelo type (see footnote 4). In that case the model also predicts a relative volatility of consumption bigger than one; labor is highly procyclical. The point estimate of $\omega$ was 0.2 denoting a positive, yet small, income effect on labor supply. The entire set of results using these preferences is available upon request.

${ }^{10}$ Minimum $\mathrm{Q}$ is the value of the quadratic form in the sample moments minimized when performing the GMM estimation. Notice that its value is increasing in the number of moments used in the estimation. Therefore, comparisons should only be made between columns 5 and 7 , and columns 6 and 8 . SSR is the sum of squared residuals between all data moments and all model-based moments, not only those used in the estimation.

${ }^{11}$ The dynamics of the other macro variables are available upon request.
} 
The benchmark model predicts a fall in consumption and output, yet it also predicts a boom in equilibrium employment, a clearly counterfactual result. This can be seen in the upper panel of Figure 1. These results are to be expected, given the sizeable income effect induced by a sudden stop driven by a large fall in the permanent component of productivity $\Gamma_{t} \cdot{ }^{12}$

The benchmark model modified to use a GHH utility predicts a large fall in consumption, and output but only a minor fall in labor, less than one percent from trend, far from the one observed in the data which is close to 2.5 percent. We plot these results in the middle panel of Figure 1. There is a fall in the permanent component of productivity $\Gamma_{t}$, which reduces consumption.

Finally, we evaluate the model in the case of a GHH utility and including data on labor for the estimation. The model predicts a large fall in consumption, and a larger fall in labor than in the previous experiment. In this case the fall in labor is larger than one percent, although still smaller than in the data. We show this in the lower panel of Figure 1. Evaluating the model along the dimensions of achieving a fall in labor of size closer to the data, as well as falls in output and consumption, this experiment has the biggest success replicating the behavior in the data. Thus the results found in the previous section when assessing business cycle moments extend to the case of sudden stop episodes.

\section{Comparing Canada and Mexico}

A central point of departure in the analysis of AG is the sharp difference in the dynamics of some of the key macroeconomic time series across developed and emerging economies, which they characterize by studying more closely Canada and Mexico. As mentioned above, these differences served as the information set used in the GMM estimation when trying to pin down the persistence -the random walk component- in the productivity process in each of the two economies. A crucial finding of AG in their comparison is that, unlike for Canada, in Mexico shocks to trend predominate over transient shocks to productivity. This led AG to conclude that, for emerging economies, "the cycle is the trend".

Considering the evidence presented in the previous two sections, we now assess whether or not these differences between Canada and Mexico are robust when employment dynamics

\footnotetext{
${ }^{12}$ For the sake of space, we do not report the dynamics of the two productivity processes. However, in all the simulations a sudden stop is reproduced only when the stochastic productivity process significantly falls below trend, a result that was already found by AG.
} 
are incorporated into the analysis. Some of the questions that we seek to answer are: does one also observe sharp differences in the labor dynamics across Mexico and Canada? If so, can trend shocks also account for them? Is "the cycle is the trend" hypothesis robust to including labor dynamics into the information set?

To answer these questions we follow a simple strategy by extending our analysis to Canada, for which we carry out parallel estimations as the four ones we did for Mexico. We then compare the characteristics of the productivity processes estimated for the two economies using the different functional forms and information sets we have thus far considered.

Our results are reported in Table 3. Again, the right part of this table presents results for the subsample for which we have data on Canadian labor statistics, 1981:I - 2002:I. An important observation comes from column 4, where it is immediate to notice that, beyond the relative lower volatility in most Canadian macro variables already documented by AG, the procyclicality of labor is much higher than in Mexico. While the output-labor correlation is only 0.55 in Mexico, it reaches 0.89 in Canada. Moreover, in Canada, employment is significantly more volatile, relative to output, compared to Mexico.

The first result comes from inspecting columns 5 through 8, particularly in the dimension of the procyclicality of labor. Differently from the Mexican case, in all estimations the correlation between labor and output is positive. The intuition behind this result can be easily explained. Because of the relatively small volatility in Canadian macro data, the GMM estimation identifies small trend shocks that do not go in conflict with procyclical labor, as was the case for Mexico. Thus the trade-off documented in the previous sections in the estimation of the model with Mexican data is more moderate now. It should be noticed, however, that the trade-off does not disappear. Adding moments of labor to the benchmark estimation mildly reduces the volatility of consumption and increases the correlation of labor and output. This can be seen by comparing columns 5 and 6 in Table 3. Notice also that the specification with GHH utility and using information on labor matches the relative volatility of consumption and produces the correlation between labor and output closest to the observed value. This can be seen by comparing columns 7 and $8 .{ }^{13}$

We now turn to discussing the differences in the persistence of the productivity processes

\footnotetext{
${ }^{13}$ The specification with GHH utility and using information on labor does not have a qualitative advantage over the other ones. The observed correlation between the trade balance and output is negative, while the predicted ones are positive. This however is mainly a consequence of the poor fit of investment volatility which we think could potentially be reduced by estimating the capital adjustment cost parameter in the model. Also, the specification does not have a better fit judging by the measures of fit at the bottom of Table 3 .
} 
across Mexico and Canada throughout the different estimations we perform. We do so by using the same metric used by AG: the magnitude of the random walk component (RWC) of productivity. ${ }^{14}$ AG found that it was nearly three times bigger for Mexico than for Canada and that it accounted for a volatility of consumption bigger than the one of output, as in Mexican data. This result holds across the specifications we have analyzed. The RWC reported in columns 5, 6, 7, and 8 in Table 2 all report a bigger RWC than the corresponding values found for Canada in Table 3. We also notice that when we estimate specifications for Mexico, using a GHH utility yields a much bigger RWC than using a Cobb-Douglas one, whether labor data are used in the estimation or not. This result comes from the fact that, when using GHH utility, the estimated value of the persistence of growth shocks, $\rho_{g}$, is bigger than when using Cobb-Douglas utility. In the case of GHH preferences and using labor moments, the case which we argue is the best specification, the RWC is more than ten times larger in Mexico than in Canada. Thus, up to this point, there is evidence that "the cycle is the trend" hypothesis is robust to including labor dynamics. We turn now to assess if this result holds when taking into account various measures of Mexican formal employment.

\section{Measurement issues}

We have thus far left aside a crucial topic in our analysis: to what extent do measurement issues in Mexican labor data make our results unreliable? As mentioned in the Introduction, AG make no claim of matching the observed labor dynamics in Mexico because of the measurement issues regarding the data on employment in emerging markets, although they do not provide further details regarding the nature of these issues.

In this last section we dig deeper into these measurement issues by focusing on two of them. First, we assess the role of the informal economy given that the employment data used by AG to compute Mexican Solow residuals, that we also use, do not distinguish between labor allocated to the formal or informal sectors of the economy. Yet, to a large extent, GDP data measures valued added produced in the formal sector of the economy. ${ }^{15}$ To make the labor input more comparable to output we adjust the employment series used in our previous estimations. Taking into account the informal sector is important because it may serve as a

\footnotetext{
${ }^{14}$ We calculate the random walk component of productivity as in AG: $\frac{\alpha^{2} \sigma_{g}^{2} /\left(1-\rho_{g}\right)^{2}}{\left[2 /\left(1+\rho_{z}\right)\right] \sigma_{z}^{2}+\left[\alpha^{2} \sigma_{g}^{2} /\left(1-\rho_{g}^{2}\right)\right]}$.

${ }^{15}$ The Mexican National Institute of Statistics (INEGI in Spanish) calculates a measurement of GDP produced by the informal sector, and is part of total GDP. It represents a small fraction, approximately $10 \%$ since this measurement started. The characteristics of these data in terms of starting date and frequency impede a straightforward calculation of a time series of formal sector GDP.
} 
buffer against large negative shocks to the economy thus reducing the procyclicality of total employment. ${ }^{16}$ A second issue we study is the one voiced by Neumeyer and Perri (2005), who mention that labor in Argentina has low volatility because employment in the public sector is used as unemployment insurance.

To address the first issue, we gather data aimed at calculating time series for employment in the formal sector of the economy. All data come from the National Survey of Urban Employment (ENEU in Spanish). Because the ENEU does not include any definition of "formal" employment, we construct alternative series for employment allocated to the informal sector and, after seasonally adjusting them, we subtract them from total employment. We are guided by the literature when constructing the following three measures. ${ }^{17}$ Formal employment 1 (FE1) is total employment minus employment in establishments with 1 to 5 employees; formal employment 2 (FE2) is total employment minus employees without benefits provided by the labor legislation; formal employment 3 (FE3) is total employment minus wage earners who do not receive benefits provided by the labor legislation. ${ }^{18}$

To address the second measurement issue we calculate total employment net of employment in the government sector. The ENEU reports the distribution of employment by sectors of economic activity, one of them being the government sector. Again, we obtain the series for employment in the government sector, adjust it for seasonality, and subtract if from total employment. If the phenomenon described by Neumeyer and Perri (2005) for Argentina is similar in Mexico, then we should observe that the constructed series are more volatile and more correlated with output.

We report in Table 4 a comparison of the properties of the four series of employment previously discussed. We calculate the HP-cyclical component of each one and report their standard deviations relative to the one of the cyclical component of GDP, as well as the correlation with cyclical GDP. We also report the size of each one of the four series relative

\footnotetext{
${ }^{16}$ The proposition that labor is mobile across formal and informal sectors in developing countries has been supported by evidence in Pratap and Quintin (2006) for Argentina, and Bosch and Maloney (2008) for Mexico and Brazil. These last authors report that informal employment is countercyclical and formal employment is procyclical.

${ }^{17}$ The first measure of formal employment is suggested by evidence that establishments in the informal sector are small. Amaral and Quintin (2006) report data for Argentina. They define formal workers as those receiving pensions and unemployment insurance benefits. These authors find that establishments with a small number of employees account for a significantly higher fraction of employment in the informal sector than in the formal one. The second measure is similar to one used by Pratap and Quintin (2006). So is the third measure.

${ }^{18}$ Benefits refer to those provided by employers or social security institutions due to the labor market legislation. One difference between FE2 and FE3 is that some individuals employed, who do not receive benefits, may not receive a wage. For example, this would be the case of relatives who work without a monetary compensation for the head of a household.
} 
to total employment. For comparison purposes we also include these statistics for total employment in Canada.

Table 4 unambiguously point to formal employment in Mexico being more volatile and procyclical than total employment. The three measures of formal employment are much more in line with those of Canada and are consistent with the above mentioned hypothesis that the informal sector serves as a buffer against negative aggregate shocks. Regarding nongovernment employment, we see that its dynamics are virtually identical to those of total employment, suggesting that the concern in Neumeyer and Perri (2007) is not an issue for Mexico: employment in the government sector does not seem to be used as a buffer against shocks.

The observations pertaining to the cyclicality of formal labor pose a challenge for "the cycle is the trend" hypothesis when assessed using formal employment data because the documented trade-off between matching consumption and labor increases. Indeed, when using the alternative measures of formal employment the model would have to match now a higher procyclicality of labor while at the same time reproducing the large volatility of consumption. As we documented above, a good match of the former would assign a relatively modest role to trend shocks while a good match of the latter would go in the opposite direction.

To formally explore this we estimate the specification that uses GHH preferences using our four alternative measures of labor. Results are reported in Table 5. For convenience we reproduce results from column 8 in Table 2, in column 2 of Table 5 . First, note that estimations that use FE1, FE2 and FE3 predict higher correlations between labor and output than previously. The model is trying to match the fact that the correlation takes higher values for each one of the measures of formal employment. Second, note that the estimations predict a volatility of consumption lower than the one of output. Confronted by the documented trade-off, the estimation gives more weight to matching the now higher procyclicality of labor thereby reducing the role of trend shocks. This explains the large reductions of the RWC. Third, this increased tension between matching the volatility of consumption and the correlation of labor reduced the overall fit of the model as documented by the two criteria at the bottom of Table 5. Fourth, note that the estimation carried out with FE4, which is non-government employment, yields basically the same results as the specification that uses total employment. This is due to the fact that total employment and non-government employment have basically the same statistical properties.

Summing up, our results suggest that measurement issues in Mexican labor data are 
indeed relevant through the effect of informality in reducing the procyclicality of total employment. This poses a challenge to "the cycle is the trend" hypothesis because trend shocks can no longer account for the large volatility of formal consumption and the strong procyclicality of formal labor. It is evident that we have only scratched the surface of a deeper topic in emerging market business cycle research and more attention needs to be devoted to study it, but this goes beyond the scope of this comment. We think that a particularly interesting avenue for research could be, for instance, to embed with labor market frictions the current vintage of emerging market business cycle models ${ }^{19}$. To the very least, we think we have made the case that future research in this area ought to include employment data into their analysis.

\section{References}

[1] Aguiar, M., and G. Gopinath (2004): "Emerging Market Business Cycles: The Cycle is the Trend," NBER Working Paper No. 10734.

[2] Aguiar, M., and G. Gopinath (2007): "Emerging Market Business Cycles: The Cycle is the Trend," Journal of Political Economy, 115, 69-102.

[3] Amaral, P., and E. Quintin (2006): "A Competitive Model of the Informal Sector," Journal of Monetary Economics 53, 1541-1553.

[4] Bosch, M. and W. Maloney (2008): "Cyclical Movements in Unemployment and Informality in Developing Countries," Discussion Paper No. 3514, IZA.

[5] Boz, E., C. B. Durdu and N. Li (2009): "Labor Market Search in Emerging Economies," working paper.

[6] Burnside, C. (1999): "Real Business Cycle Models: Linear Approximation and GMM estimation," working paper.

[7] Correia, I., J. Neves, and S. Rebelo (1995): "Business cycles in a small open economy," European Economic Review, 39, 1089-1113.

\footnotetext{
${ }^{19}$ Three examples of recent research in this direction are Boz, Durdu and Li (2009), and Lama and Urrutia (2011), who embed matching frictions of the Mortensen-Pissarides type in the labor market of an emerging economy; and Meza and Quintin (2007) where a small open economy model is extended to include labor hoarding.
} 
[8] Greenwood, J., Z. Hercowitz, and G. Huffman (1988): "Investment Capacity Utilization and the Real Business Cycle," American Economic Review, 78, 402-417.

[9] Jaimovich, N., and S. Rebelo (2009): "Can News about the Future Drive the Business Cycle?," American Economic Review 99, 1097-1118.

[10] King, R. G., C.I. Plosser, and S. Rebelo (1988): "Production, Growth and Business Cycles: I. The Basic Neoclassical Model," Journal of Monetary Economics, 21, 195232.

[11] Lama, R., and C. Urrutia (2011): "Employment Protection and Business Cycles in Emerging Economies " working paper.

[12] Meza, F. and E. Quintin (2007): "Factor utilization and the real impact of financial crises," The B.E. Journal of Macroeconomics, Vol. 7: Issue 1 (Advances), Article 33.

[13] Mendoza, E.G. (2010): "Sudden Stops, Financial Crises and Leverage," American Economic Review 100, 1941-1966.

[14] Neumeyer, P.A. and F. Perri (2005):"Business cycles in emerging economies: the role of interest rates," Journal of Monetary Economics, 52, 345-380.

[15] Pratap, S. and E. Quintin (2006): "Are labor markets segmented in developing countries? A semiparametric approach," European Economic Review, 50, 1817-1841. 
Table 1. Calibrated parameters

\begin{tabular}{|l|c|c|c|}
\hline & Symbol & Cobb-Douglas utility $^{1}$ & GHH $^{\text {utility }}{ }^{2}$ \\
\hline Time preference rate & $\beta$ & 0.98 & 0.98 \\
\hline Labor exponent (utility) & $v$ & NR & 1.6 \\
\hline Labor coefficient (utility) & $\tau$ & NR & 1.4 \\
\hline Consumption exponent (utility) & $\gamma$ & 0.36 & NR \\
\hline Steady-state debt to GDP & $b$ & $10 \%$ & $10 \%$ \\
\hline Coefficient on interest rate premium & $\psi$ & 0.001 & 0.001 \\
\hline Labor exponent (production) & $\alpha$ & 0.68 & 0.68 \\
\hline Risk aversion & $\sigma$ & 2 & 2 \\
\hline Depreciation rate & $\delta$ & 0.05 & 0.05 \\
\hline Capital adjustment cost & $\varphi$ & 4 & 4 \\
\hline
\end{tabular}

1 Values taken from Aguiar and Gopinath (2007), Table 3. NR stands for not required.

2 Values taken from Aguiar and Gopinath (2004), Table 3, except the one for $\varphi$. In Aguiar and Gopinath (2004) it was estimated. We use the same value as in Aguiar and Gopinath (2007), in Table 3. Also, for the depreciation rate we use the same value as in Aguiar and Gopinath (2007), Table 3. NR stands for not required. 
Table 2. Mexico: data, estimated parameters and predicted moments

\begin{tabular}{|c|c|c|c|c|c|c|c|c|}
\hline \multirow[b]{3}{*}{$\begin{array}{l}\text { Estimated } \\
\text { Parameters }\end{array}$} & \multirow{2}{*}{\multicolumn{3}{|c|}{$\begin{array}{l}\text { Using entire sample (1980.I - 2003:II) } \\
\text { Using Cobb-Douglas utility } \\
\text { Moments used in estimation: } \\
\sigma(y), \sigma(c), \operatorname{cov}(y, c)^{1}\end{array}$}} & \multicolumn{5}{|c|}{ Using subsample for which we have labor data (1987.I - 2003:II) } \\
\hline & & & & \multirow[b]{2}{*}{ (4) } & \multicolumn{2}{|c|}{ Using Cobb-Douglas utility } & \multicolumn{2}{|c|}{ Using GHH utility } \\
\hline & (1) & $\begin{array}{c}(2) \\
A G(2007)^{3}\end{array}$ & $\begin{array}{c}\text { (3) } \\
\text { Replication }\end{array}$ & & $\begin{array}{c}\text { (5) } \\
A G \\
\text { specification }\end{array}$ & $\begin{array}{c}\text { (6) } \\
\text { Adding } \sigma(h) \\
\operatorname{cov}(y, h) \text { in } \\
\text { GMM }\end{array}$ & $\begin{array}{c}\text { (7) } \\
A G \\
\text { specification }\end{array}$ & $\begin{array}{c}\text { (8) } \\
\text { Adding } \sigma(h), \\
\operatorname{cov}(y, h) \text { in } \\
\text { GMM }\end{array}$ \\
\hline$\sigma_{g}$ & & $2.55(0.52)$ & $2.55(0.50)$ & & $2.48(0.67)$ & $1.36(0.36)$ & $1.00(0.27)$ & $0.47(0.06)$ \\
\hline$\sigma_{z}$ & & $0.54(0.22)$ & $0.53(0.23)$ & & $0.37(0.44)$ & $0.26(0.47)$ & $0.00(86834.06)$ & $0.48(0.09)$ \\
\hline$\rho_{g}$ & & $0.11(0.10)$ & $0.1093(0.10)$ & & $0.1461(0.13)$ & $0.3611(0.08)$ & $0.8072(0.04)$ & $0.8989(0.02)$ \\
\hline RWC & & 1.1356 & $1.14(0.29)$ & & $1.28(0.44)$ & $1.99(0.77)$ & $9.37(2.94)$ & $12.94(2.52)$ \\
\hline \multicolumn{9}{|c|}{ Population and model based moments } \\
\hline $\begin{array}{l}\text { Population } \\
\text { moments }\end{array}$ & $\begin{array}{c}\text { Mexican } \\
\text { Data }\end{array}$ & & & $\begin{array}{c}\text { Mexican } \\
\text { Data }\end{array}$ & & & & \\
\hline$\sigma(y)$ & $2.40(0.34)$ & 2.41 & $2.40(0.34)$ & $2.32(0.49)$ & $2.32(0.49)$ & $1.67(0.43)$ & $2.47(0.46)$ & $1.91(0.25)$ \\
\hline$\sigma(\Delta y)$ & $1.64(0.21)$ & 1.56 & $1.56(0.38)$ & $1.61(0.29)$ & $1.43(0.52)$ & $0.91(0.33)$ & $1.47(0.34)$ & $1.27(0.18)$ \\
\hline$\sigma(c) / \sigma(y)$ & $1.26(0.08)$ & 1.2611 & $1.26(0.08)$ & $1.31(0.11)$ & $1.31(0.11)$ & $1.29(0.13)$ & $1.27(0.09)$ & $1.22(0.05)$ \\
\hline$\sigma(I) / \sigma(y)$ & $4.15(0.28)$ & 2.6629 & $2.67(0.14)$ & $3.80(0.22)$ & $2.75(0.19)$ & $2.76(0.19)$ & $3.27(0.26)$ & $3.11(0.12)$ \\
\hline$\sigma(n x) / \sigma(y)$ & $0.90(0.09)$ & 0.7854 & $0.79(0.13)$ & $0.79(0.07)$ & $0.85(0.19)$ & $1.08(0.22)$ & $0.97(0.16)$ & $1.07(0.09)$ \\
\hline$\sigma(\mathrm{h}) / \sigma(y)$ & NA & NA & NA & $0.42(0.05)$ & $0.38(0.09)$ & $0.54(0.10)$ & $0.48(0.06)$ & $0.47(0.02)$ \\
\hline$\rho(y)$ & $0.83(0.07)$ & 0.8303 & $0.83(0.05)$ & $0.82(0.11)$ & $0.85(0.07)$ & $0.90(0.04)$ & $0.90(0.04)$ & $0.87(0.01)$ \\
\hline$\rho(\Delta y)$ & $0.37(0.09)$ & 0.3069 & $0.31(0.22)$ & $0.44(0.10)$ & $0.42(0.34)$ & $0.64(0.30)$ & $0.53(0.21)$ & $0.45(0.07)$ \\
\hline$\rho(y, n x)$ & $-0.75(0.08)$ & -0.5484 & $-0.55(0.07)$ & $-0.83(0.08)$ & $-0.56(0.09)$ & $-0.21(0.07)$ & $-0.46(0.07)$ & $-0.22(0.03)$ \\
\hline$\rho(y, c)$ & $0.92(0.02)$ & 0.9152 & $0.92(0.02)$ & $0.92(0.03)$ & $0.92(0.03)$ & $0.78(0.05)$ & $0.91(0.03)$ & $0.82(0.03)$ \\
\hline$\rho(y, I)$ & $0.91(0.03)$ & 0.8881 & $0.89(0.05)$ & $0.95(0.02)$ & $0.87(0.07)$ & $0.71(0.10)$ & $0.76(0.06)$ & $0.67(0.03)$ \\
\hline$\rho(y, h)$ & NA & NA & NA & $0.55(0.13)$ & $-0.36(0.10)$ & $-0.02(0.08)$ & $-0.34(0.37)$ & $0.30(0.12)$ \\
\hline Minimum $\mathrm{Q}^{4}$ & & & $7.9389 \times 10^{-28}$ & & $4.4590 \times 10^{-28}$ & 3.3967 & 0.9871 & 3.2363 \\
\hline SSR & & & 0.2394 & & 3.0970 & 3.6259 & 3.6217 & 1.3433 \\
\hline
\end{tabular}

1 Notation $\sigma(x), \operatorname{cov}(x, y), \rho(x), \rho(x, y), \Delta x$ stand for standard deviation of a variable $x$, covariance between variables $x$ and $y$, autocorrelation of $x$, correlation between $x$ and $y$, and change in variable $x$, respectively. Variables $y, c, l, n x, h$ stand for output, consumption, investment, net exports-to-output ratio and labor, respectively. All variables are in logarithms, except for net export share. All variables have been HP-filtered, except the change in output. Values of standard deviations are reported in percent. NA stands for not available.

2 Parameters $\sigma_{g}, \sigma_{z}$ and $\rho_{g}$ are defined in the text. RWC stands for the random walk component of productivity. Standard errors are in parentheses.

3 AG stands for Aguiar and Gopinath (2007). Aguiar and Gopinath (2007) do not report the model-based moments for this particular case. However, one is able to recover them by extending their codes in a straightforward manner.

4 Minimum $Q$ is the value of the quadratic form in the sample moments minimized when performing the GMM estimation. SSR is the sum of squared residuals between all data moments and all model-based moments, not only those used in the estimation. 
Table 3. Canada: data, estimated parameters and predicted moments

\begin{tabular}{|c|c|c|c|c|c|c|c|c|}
\hline \multirow[b]{3}{*}{$\begin{array}{l}\text { Estimated } \\
\text { Parameters }{ }^{2}\end{array}$} & \multirow{2}{*}{\multicolumn{3}{|c|}{$\begin{array}{l}\text { Using entire sample (1981.I - 2003:II) } \\
\text { Using Cobb-Douglas utility } \\
\text { Moments used in estimation: } \\
\sigma(y), \sigma(c), \operatorname{cov}(y, c)^{1}\end{array}$}} & \multicolumn{5}{|c|}{ Using subsample for which we have labor data (1981.I - 2002:I) } \\
\hline & & & & & \multicolumn{2}{|c|}{ Using Cobb-Douglas utility } & \multicolumn{2}{|c|}{ Using GHH utility } \\
\hline & (1) & $\begin{array}{c}(2) \\
A G(2007)^{3}\end{array}$ & $\begin{array}{c}\text { (3) } \\
\text { Replication }\end{array}$ & (4) & $\begin{array}{c}\text { (5) } \\
\text { AG } \\
\text { specification }\end{array}$ & $\begin{array}{c}\text { (6) } \\
\text { Adding } \sigma(h) \\
\operatorname{cov}(y, h) \text { in } \\
\text { GMM }\end{array}$ & $\begin{array}{c}(7) \\
A G \\
\text { specification }\end{array}$ & $\begin{array}{c}\text { (8) } \\
\text { Adding } \sigma(h) \\
\operatorname{cov}(y, h) \text { in } \\
\text { GMM }\end{array}$ \\
\hline$\sigma_{g}$ & & $0.87(0.61)$ & $0.88(0.60)$ & & $1.27(0.68)$ & $0.19(0.07)$ & $1.82(0.43)$ & $0.77(0.13)$ \\
\hline$\sigma_{z}$ & & $0.78(0.08)$ & $0.78(0.08)$ & & $0.74(0.31)$ & $0.66(0.08)$ & $0.00(55594.75)$ & $0.59(0.08)$ \\
\hline$\rho_{g}$ & & $0.03(0.54)$ & $0.0230(0.53)$ & & $-0.3607(0.81)$ & $0.7848(0.06)$ & $-0.3280(0.08)$ & $-0.6698(0.13)$ \\
\hline RWC & & 0.3818 & $0.38(0.13)$ & & $0.29(0.25)$ & $0.71(0.19)$ & $0.51(0.15)$ & $0.11(0.06)$ \\
\hline \multicolumn{9}{|c|}{ Population and model based moments } \\
\hline $\begin{array}{l}\text { Population } \\
\text { moments }\end{array}$ & $\begin{array}{c}\text { Canadian } \\
\text { Data }\end{array}$ & & & $\begin{array}{c}\text { Canadian } \\
\text { Data }\end{array}$ & & & & \\
\hline$\sigma(y)$ & $1.55(0.20)$ & 1.55 & $1.55(0.20)$ & $1.58(0.20)$ & $1.58(0.20)$ & $1.33(0.16)$ & $1.94(0.16)$ & $1.74(0.16)$ \\
\hline$\sigma(\Delta y)$ & $1.04(0.08)$ & 1.14 & $1.14(0.29)$ & $1.06(0.08)$ & $1.43(0.86)$ & $0.95(0.11)$ & $3.03(0.52)$ & $2.11(0.21)$ \\
\hline$\sigma(c) / \sigma(y)$ & $0.74(0.05)$ & 0.7441 & $0.74(0.05)$ & $0.75(0.05)$ & $0.75(0.05)$ & $0.69(0.06)$ & $0.78(0.03)$ & $0.75(0.01)$ \\
\hline$\sigma(\mathrm{l}) / \sigma(\mathrm{y})$ & $2.67(0.26)$ & 2.0108 & $2.01(0.06)$ & $2.68(0.26)$ & $1.93(0.32)$ & $1.87(0.09)$ & $1.25(0.53)$ & $1.70(0.07)$ \\
\hline$\sigma(n x) / \sigma(y)$ & $0.57(0.09)$ & 0.4217 & $0.42(0.13)$ & $0.53(0.08)$ & $0.41(0.20)$ & $0.83(0.08)$ & $0.47(0.11)$ & $0.34(0.03)$ \\
\hline$\sigma(\mathrm{h}) / \sigma(\mathrm{y})$ & NA & NA & NA & $0.73(0.04)$ & $0.33(0.05)$ & $0.57(0.03)$ & $0.92(0.13)$ & $0.75(0.02)$ \\
\hline$\rho(y)$ & $0.93(0.05)$ & 0.7546 & $0.75(0.08)$ & $0.93(0.05)$ & $0.61(0.59)$ & $0.77(0.01)$ & $-0.21(0.52)$ & $0.29(0.09)$ \\
\hline$\rho(\Delta y)$ & $0.74(0.07)$ & 0.0484 & $0.05(0.19)$ & $0.73(0.07)$ & $-0.25(0.98)$ & $0.07(0.02)$ & $-0.64(0.08)$ & $-0.62(0.07)$ \\
\hline$\rho(y, n x)$ & $-0.12(0.18)$ & 0.1705 & $0.17(0.13)$ & $-0.21(0.18)$ & $0.19(0.33)$ & $0.49(0.05)$ & $0.54(0.21)$ & $0.38(0.07)$ \\
\hline$\rho(y, c)$ & $0.87(0.05)$ & 0.8672 & $0.87(0.05)$ & $0.88(0.05)$ & $0.88(0.05)$ & $0.54(0.05)$ & $0.95(0.03)$ & $0.98(0.00)$ \\
\hline$\rho(y, I)$ & $0.74(0.08)$ & 0.9341 & $0.94(0.05)$ & $0.74(0.08)$ & $0.93(0.13)$ & $0.72(0.06)$ & $0.61(0.24)$ & $0.80(0.04)$ \\
\hline$\rho(y, h)$ & NA & NA & NA & $0.89(0.04)$ & $0.69(0.06)$ & $0.74(0.05)$ & $0.73(0.10)$ & $0.93(0.02)$ \\
\hline Minimum $\mathrm{Q}^{4}$ & & & $4.4391 \times 10^{-29}$ & & $1.8496 \times 10^{-28}$ & 5.4443 & 4.9392 & 7.3655 \\
\hline SSR & & & 7.2778 & & 7.1092 & 12.9563 & 27.3813 & 15.8127 \\
\hline
\end{tabular}

1 Notation $\sigma(x), \operatorname{cov}(x, y), \rho(x), \rho(x, y), \Delta x$ stand for standard deviation of a variable $x$, covariance between variables $x$ and $y$, autocorrelation of $x$, correlation between $x$ and $y$, and change in variable $\mathrm{x}$, respectively. Variables $\mathrm{y}, \mathrm{c}, \mathrm{l}, \mathrm{nx}$, h stand for output, consumption, investment, net exports and labor, respectively. All variables are in logarithms, except for net exports. All variables have been HP-filtered, except the change in output. Values of standard deviations are reported in percent. NA stands for not available.

2 Parameters $\sigma_{g}, \sigma_{z}$ and $\rho_{g}$ are defined in the text. RWC stands for the random walk component of productivity. Standard errors are in parentheses.

3 AG stands for Aguiar and Gopinath (2007). Aguiar and Gopinath (2007) do not report the model-based moments for this particular case. One is able to recover them by modifying their codes.

4 Minimum $Q$ is the value of the quadratic form in the sample moments minimized when performing GMM. SSR is the sum of squared residuals between all data moments and all model-based moments, not only those used in the estimation. 
Table 4. Statistics of alternative series of employment in Mexico

\begin{tabular}{|l|c|c|c|}
\hline & $\begin{array}{c}\text { Relative volatility } \\
\text { compared to GDP } \\
\sigma(\mathrm{h}) / \sigma(\mathrm{y})\end{array}$ & $\begin{array}{c}\text { Correlation with } \\
\text { GDP } \\
\rho(\mathrm{y}, \mathrm{h})\end{array}$ & $\begin{array}{c}\text { Fraction of total } \\
\text { employment, in \% }\end{array}$ \\
\hline Total employment & 0.43 & 0.53 & 100 \\
\hline Formal employment 1 & 0.79 & 0.84 & 58 \\
\hline Formal employment 2 & 0.93 & 0.84 & 77 \\
\hline Formal employment 3 & 1.08 & 0.64 & 94 \\
\hline Net of government sector & 0.44 & 0.55 & 100 \\
\hline Canadian total employment & 0.73 & 0.89 & \\
\hline
\end{tabular}

1 Notation $\sigma(x)$ and $\rho(x, y)$ stand for standard deviation of a variable $\mathrm{x}$ and correlation between variables $\mathrm{x}$ and $\mathrm{y}$. Variables $\mathrm{y}$ and $\mathrm{h}$ stand for output and labor, respectively. All variables are in logarithms. All variables have been HP-filtered.

2 Formal employment 1 is total employment minus employment in establishments with 1 to 5 employees; formal employment 2 is total employment minus employees without benefits provided by the labor legislation; formal employment 3 is total employment minus wage earners who do not receive benefits provided by the labor legislation. Net of government sector is total employment minus government employment. Source of the raw data: INEGI. 
Table 5. Comparing estimations with different measures of formal employment, and non-government employment, in Mexico

\begin{tabular}{|c|c|c|c|c|c|c|c|c|c|c|}
\hline \multicolumn{11}{|c|}{$\begin{array}{l}\text { Using subsample for which we have labor data }(1987.1-2003: I) \\
\text { Moments used in all estimations: } \sigma(y), \sigma(c), \operatorname{cov}(y, c)^{1}\end{array}$} \\
\hline & \multicolumn{2}{|c|}{$\begin{array}{l}\text { GHH utility with total } \\
\text { employment }\end{array}$} & \multicolumn{2}{|c|}{$\begin{array}{l}\text { GHH utility with Formal } \\
\text { Employment } 1\end{array}$} & \multicolumn{2}{|c|}{$\begin{array}{l}\text { GHH utility with Formal } \\
\text { Employment } 2\end{array}$} & \multicolumn{2}{|c|}{$\begin{array}{l}\text { GHH utility with Formal } \\
\text { Employment } 3\end{array}$} & \multicolumn{2}{|c|}{$\begin{array}{l}\text { GHH utility with Non- } \\
\text { government employment }\end{array}$} \\
\hline $\begin{array}{l}\text { Estimated } \\
\text { Parameters }\end{array}$ & (1) & $\begin{array}{c}\text { (2) } \\
\text { Adding sd(h), } \\
\text { cov(y,h) in } \\
\text { GMM }\end{array}$ & (3) & $\begin{array}{c}(4) \\
\text { Adding sd(h), } \\
\text { cov(y,h) in } \\
\text { GMM }\end{array}$ & (5) & $\begin{array}{c}(6) \\
\text { Adding sd(h), } \\
\operatorname{cov}(y, h) \text { in } \\
\text { GMM }\end{array}$ & (7) & $\begin{array}{c}(8) \\
\text { Adding } \sigma(h), \\
\operatorname{cov}(y, h) \text { in } \\
\text { GMM }\end{array}$ & (9) & $\begin{array}{c}\text { (10) } \\
\text { Adding } \sigma(\mathrm{h}), \\
\text { cov }(\mathrm{y}, \mathrm{h}) \text { in } \\
\mathrm{GMM}\end{array}$ \\
\hline$\sigma_{g}$ & & $0.47(0.06)$ & & $1.45(0.25)$ & & $2.13(0.19)$ & & $2.54(0.39)$ & & $0.47(0.05)$ \\
\hline$\sigma_{z}$ & & $0.48(0.09)$ & & $0.67(0.13)$ & & $0.00(2844.9)$ & & 0.00 (11999) & & $0.47(0.11)$ \\
\hline$\rho_{g}$ & & $0.90(0.02)$ & & $0.36(0.20)$ & & $0.05(0.17)$ & & $0.07(0.16)$ & & $0.90(0.02)$ \\
\hline RWC & & $12.94(2.52)$ & & $1.50(0.48)$ & & $1.09(0.23)$ & & $1.14(0.17)$ & & $13.23(2.76)$ \\
\hline $\begin{array}{l}\text { Population } \\
\text { moments }\end{array}$ & $\begin{array}{l}\text { Mexican } \\
\text { Data }\end{array}$ & & $\begin{array}{c}\text { Mexican } \\
\text { Data }\end{array}$ & & $\begin{array}{l}\text { Mexican } \\
\text { Data }\end{array}$ & & $\begin{array}{l}\text { Mexican } \\
\text { Data }\end{array}$ & & $\begin{array}{l}\text { Mexican } \\
\text { Data }\end{array}$ & \\
\hline$\sigma(y)$ & $2.32(0.49)$ & $1.91(0.25)$ & $2.32(0.49)$ & $2.40(0.23)$ & $2.32(0.49)$ & $2.26(0.35)$ & $2.32(0.49)$ & $2.71(0.42)$ & $2.32(0.49)$ & $1.90(0.26)$ \\
\hline$\sigma(\Delta y)$ & $1.61(0.29)$ & $1.27(0.18)$ & $1.61(0.29)$ & $2.12(0.21)$ & $1.61(0.29)$ & $2.87(0.26)$ & $1.61(0.29)$ & $3.39(0.49)$ & $1.61(0.29)$ & $1.26(0.19)$ \\
\hline$\sigma(c) / \sigma(y)$ & $1.31(0.11)$ & $1.22(0.05)$ & $1.31(0.11)$ & $0.96(0.04)$ & $1.31(0.11)$ & $0.93(0.04)$ & $1.31(0.11)$ & $0.94(0.02)$ & $1.31(0.11)$ & $1.23(0.06)$ \\
\hline$\sigma(\mathrm{I}) / \sigma(\mathrm{y})$ & $3.80(0.22)$ & $3.11(0.12)$ & $3.80(0.22)$ & $2.17(0.19)$ & $3.80(0.22)$ & $1.77(0.33)$ & $3.80(0.22)$ & $1.80(0.33)$ & $3.80(0.22)$ & $3.13(0.14)$ \\
\hline$\sigma(n x) / \sigma(y)$ & $0.79(0.07)$ & $1.07(0.09)$ & $0.79(0.07)$ & $0.30(0.04)$ & $0.79(0.07)$ & $0.38(0.08)$ & $0.79(0.07)$ & $0.37(0.09)$ & $0.79(0.07)$ & $1.08(0.10)$ \\
\hline$\sigma(h) / \sigma(y)$ & $0.42(0.05)$ & $0.47(0.02)$ & $0.79(0.07)$ & $0.72(0.06)$ & $0.93(0.10)$ & $0.87(0.10)$ & $1.07(0.24)$ & $0.87(0.12)$ & $0.43(0.06)$ & $0.47(0.03)$ \\
\hline$\rho(y)$ & $0.82(0.11)$ & $0.87(0.01)$ & $0.82(0.11)$ & $0.64(0.13)$ & $0.82(0.11)$ & $0.21(0.35)$ & $0.82(0.11)$ & $0.23(0.39)$ & $0.82(0.11)$ & $0.87(0.02)$ \\
\hline$\rho(\Delta y)$ & $0.44(0.10)$ & $0.45(0.07)$ & $0.44(0.10)$ & $-0.11(0.15)$ & $0.44(0.10)$ & $-0.42(0.15)$ & $0.44(0.10)$ & $-0.40(0.17)$ & $0.44(0.10)$ & $0.46(0.08)$ \\
\hline$\rho(y, n x)$ & $-0.83(0.08)$ & $-0.22(0.03)$ & $-0.83(0.08)$ & $-0.62(0.16)$ & $-0.83(0.08)$ & $-0.09(0.40)$ & $-0.83(0.08)$ & $-0.14(0.39)$ & $-0.83(0.08)$ & $-0.22(0.03)$ \\
\hline$\rho(y, c)$ & $0.92(0.03)$ & $0.82(0.03)$ & $0.92(0.03)$ & $0.98(0.00)$ & $0.92(0.03)$ & $0.97(0.02)$ & $0.92(0.03)$ & $0.97(0.02)$ & $0.92(0.03)$ & $0.82(0.03)$ \\
\hline$\rho(y, l)$ & $0.95(0.02)$ & $0.67(0.03)$ & $0.95(0.02)$ & $0.96(0.01)$ & $0.95(0.02)$ & $0.85(0.12)$ & $0.95(0.02)$ & $0.86(0.12)$ & $0.95(0.02)$ & $0.67(0.03)$ \\
\hline$\rho(y, h)$ & $0.55(0.13)$ & $0.30(0.12)$ & $0.85(0.05)$ & $0.51(0.07)$ & $0.86(0.05)$ & $0.49(0.06)$ & $0.66(0.05)$ & $0.47(0.04)$ & $0.57(0.13)$ & $0.28(0.14)$ \\
\hline Minimum $Q^{4}$ & & 3.2363 & & 6.8792 & & 6.3377 & & 6.3781 & & 3.1240 \\
\hline SSR & & 1.3433 & & 3.0410 & & 8.9733 & & 9.3630 & & 1.4324 \\
\hline
\end{tabular}

1 Notation $\sigma(x), \operatorname{cov}(x, y), \rho(x), \rho(x, y), \Delta x$ stand for standard deviation of a variable $x$, covariance between variables $x$ and $y$, autocorrelation of $x$, correlation between $x$ and $y$, and change in variable $x$, respectively. Variables $y, c, l, n x, h$ stand for output, consumption, investment, net exports and labor, respectively. All variables are in logarithms, except for net exports. All variables have been HP-filtered, except the change in output. Values of standard deviations are reported in percent. NA stands for not available.

2 Parameters $\sigma_{g}, \sigma_{z}$ and $\rho_{g}$ are defined in the text. RWC stands for the random walk component of productivity. Standard errors are in parentheses.

3 AG stands for Aguiar and Gopinath (2007). Aguiar and Gopinath (2007) do not report the model-based moments for this particular case. One is able to recover them by modifying their codes.

4 Minimum $Q$ is the value of the quadratic form in the sample moments minimized when performing GMM. SSR is the sum of squared residuals between all data moments and all model-based moments, not only those used in the estimation. 
Figure 1. Sudden stop events: data and predictions (continued on next page)

A. Model with Cobb-Douglas utility and GMM estimation excluding moments of labor
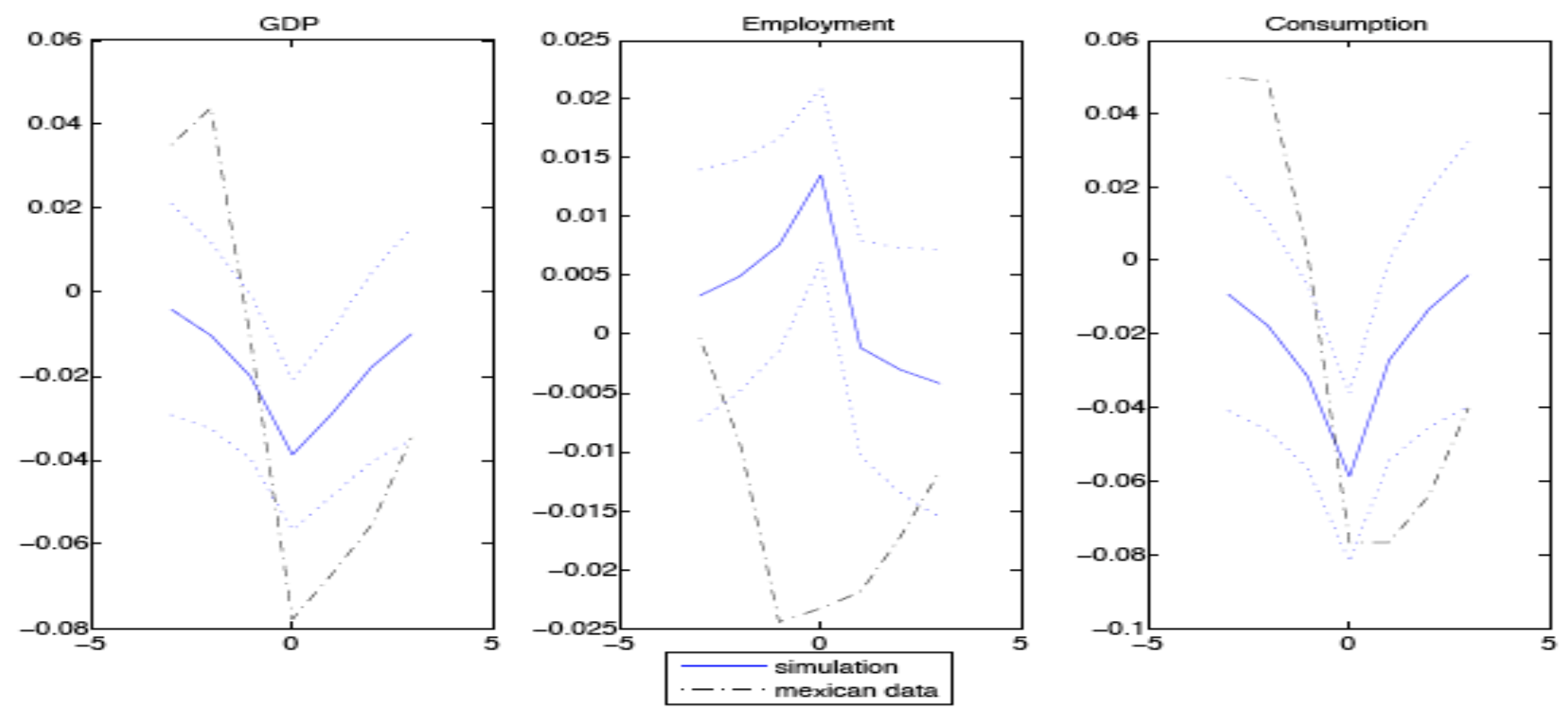

B. Model with GHH utility and GMM estimation excluding moments of labor
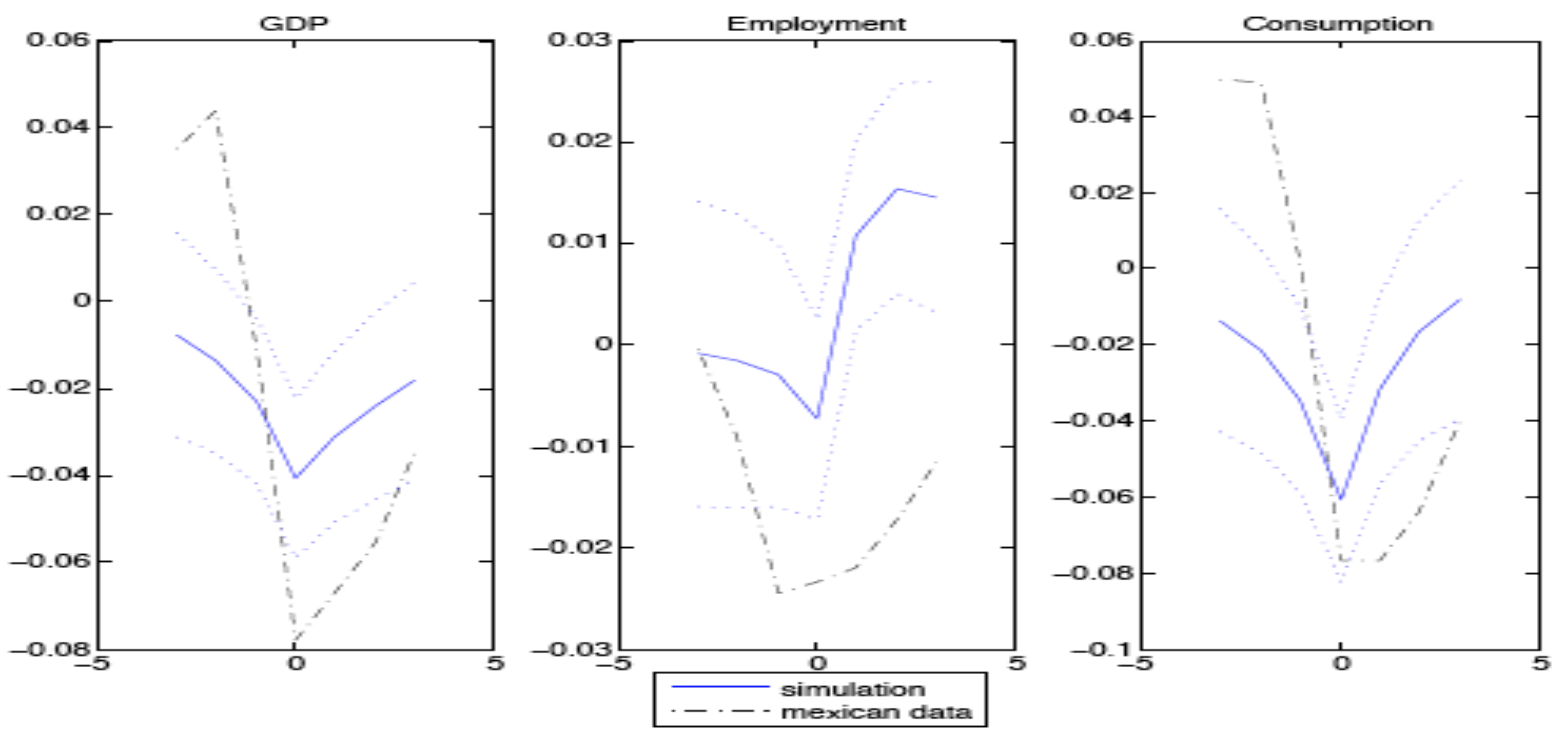


\section{Model with GHH utility and GMM estimation including moments of labor}
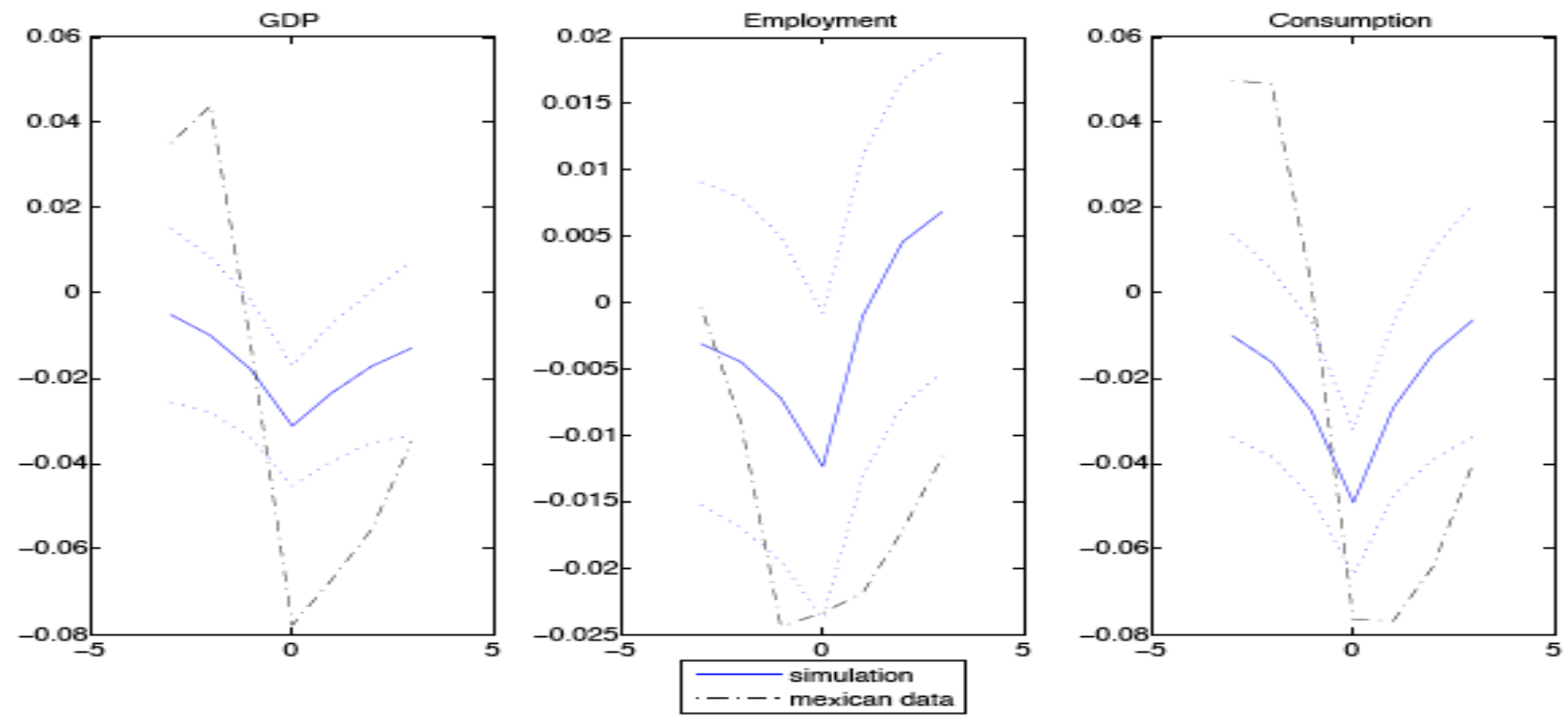

Note:

The timing for the Mexican sudden stop episode (i.e. $t=0$ ) is 1995:Il. The figures depict the evolution of macroeconomic time series in the vicinity of this episode, three quarters before and after. We carry out 1000 simulations, each one of the same length as the one of the data sample we use, which is 66 quarters. We plot the median across sudden stop episodes. Predictions are presented together with error bands. Error bands are computed as plus/minus one and a half standard deviations. 